\title{
Characterization of proteins regulated by interleukin-4 in 3T3-L1 adipocytes
}

\author{
Ming-Yuh Shiau ${ }^{1 \dagger}$, Hsu-Feng Lu ${ }^{2 \dagger}$, Yih-Hsin Chang ${ }^{3 \dagger}$, Yen-Chih Chiu ${ }^{3}$ and Yung-Luen Shih ${ }^{4,5,6^{*}}$
}

\begin{abstract}
Obesity is closely associated with metabolic syndrome, type 2 diabetes mellitus (T2DM) and cardiovascular diseases. Our previous reports uncover the significant associations between interleukin-4 (IL-4)/IL-4 receptor genotypes and T2DM, as well as IL-4 genotypes and high density lipoprotein-cholesterol. Theses observations suggest that IL-4 harbors the capacity to regulate lipid metabolism. The present study is aimed at further elucidating regulatory roles of IL-4 to lipid metabolism by identifying putative proteins in 3T3-L1 adipocytes which are differentially expressed under IL-4 treatment. Proteins in mature 3T3-L1 adipocytes with altered expression levels under IL-4 treatment were identified by proteomic strategy. Our results revealed that IL-4 up-regulated levels of ATP synthase $\delta$ chain, Cytochrome $c$ reductase, Pyrophsphatase and Vimentin, whereas, Alpha-enolase, Gelsolin, Vinculin and Valosin were down-regulated. These observations suggest that IL-4 promotes energy metabolism and inhibit lipid deposits in adipocytes by up-regulating proteins accelerating ATP synthesis. Our results suggest that IL-4 facilitates adipocytes metabolism to catabolism with a favorable condition for lipolysis. These catabolized lipids in adipocytes triggered by IL-4 might either be released into periphery or metabolized intracellularlly, and modulate systemic energy metabolism.
\end{abstract}

Keywords: Interleukin-4; Adipocytes; Metabolism; Proteomics

\section{Background}

Obesity is characterized by excess accumulation of lipids in intra-abdominal adipose tissue. The enlargement of adipose tissue is a combination of increased cell number (hyperplasia), size (hypertrophy) and formation (adipogenesis) of adipocytes (Cornelius et al. 1994; Sorisky 1999). Obesity has become an epidemic problem globally, affecting persons of all ages in both developed and developing countries. In 2010, the World Health Organization (WHO) estimated that about 2.1 billion adults were overweight (body Mass Index $[\mathrm{BMI}]>25$ ), and at least 400 million of them were obese $(\mathrm{BMI}>30)$ (World Health Organization 2014). Obesity is also the major risk factor leading to insulin resistance and type 2 diabetes mellitus (T2DM), with $44 \%$ of the diabetic burden are attributable to overweight and obesity. Moreover, overweight and obesity are leading risks for global deaths, causing death

\footnotetext{
* Correspondence: t005524@ms.skh.org.tw

${ }^{\dagger}$ Equal contributors

${ }^{4}$ Department of Pathology and Laboratory Medicine, Shin Kong Wu Ho-Su

Memorial Hospital, Taipei, Taiwan

${ }^{5}$ School of Medical Laboratory Science and Biotechnology, Taipei Medical University, Taipei, Taiwan

Full list of author information is available at the end of the article
}

toll of 3.4 million adults each year. Therefore, obesity has become an epidemic health problem due to its global increasing prevalence and its close association with multiple metabolic abnormalities.

Adipose tissue is an important endocrine organ that secretes a variety of biologically active molecules (adipokines) (Bradley et al. 2005; Trayhurn and Beattie 2001). In addition to regulating energy metabolism, these adipokines also take part in immune responses and cardiovascular tone. Dysregulated production of these adipokines is implicated in obesity and related metabolic consequences (Chaldakov et al. 2003; Lyon et al. 2003). IL-6, one of the type $2 \mathrm{~T}$ helper cell (Th2) cytokines with the activity to specifically regulate Th1/Th2 balance, is elevated in T2DM subjects (Paul and Seder 1994). Accordingly, immune responses are suggested to play certain roles in obesity and the closely related metabolic abnormalities. In this context, differentially expressed proteins of adipocytes in response to external stimuli may regulate adipocyte behavior and contribute to metabolic abnormalities.

Interleukin-4 (IL-4) is another Th2 cytokine which mediates Th1/Th2 balance and immune responses by

\section{实}


regulating the production of pro-inflammatory mediators from macrophages (Paul 1997; Garcia-Zepeda et al. 1996; Kang et al. 2008). Our previous reports identified the association between $I L-4 / I L-4 R$ genotypes and T2DM, as well as between $I L-4$ genotypes and high density lipoprotein-cholesterol (HDL-C) (Ho et al. 2010; Chang et al. 2012a). Our animal study reveals that IL-4 participates in lipid metabolism by inhibiting triglyceride accumulation in fat tissues, which leads to decreased weight gain and fat mass (Chang et al. 2012b). It suggests that IL-4 is involved in diabetic susceptibility and complications through its capacity of regulating insulin sensitivity, glucose tolerance and lipid metabolism. Our observations echo the hypothesis from Elbe-Burger et al. that IL-4 participates in lipid metabolism (Elbe-Burger et al. 2002). Our most recent report indicates that IL-4 harbors antilipogenic ability by suppressing adipocytes differentiation and promoting lipolysis in mature adipocytes (Tsao et al. 2014). The above results indicate that IL-4 regulates energy metabolism by promoting catabolism rather than energy storage through modulating adipocytes behaviors.

In this context, the aim of the present study is to identify the effects of IL-4 on protein expression profiles of adipocytes by proteomic strategy for further addressing the role of IL-4 in metabolism and metabolic pathogenesis. Our results suggest that IL-4 potentiates adipocytes metabolism to catabolism with a favorable condition for lipid decomposition. These catabolized lipids in adipocytes triggered by IL- 4 might either be released into periphery or metabolized intracellularlly, and subsequently modulate systemic energy metabolism.

\section{Results and discussion}

IL-4 has been suggested to participate in lipid metabolism by inducing peroxisome proliferator-activated receptor- $\gamma$ expression in macrophages and monocytes (Ricote et al. 2000; Elbe-Burger et al. 2002). In support of the above hypothesis, our previous study reveals that IL-4 promotes lipolysis by boosting hormone sensitive lipase (HSL) activity and translocation in adipocytes. It indicates that the decrease of lipid deposits in adipocytes under IL-4 treatment results from the pro-lipolytic activity of IL-4 through modulating HSL activity to inhibit adipocytes differentiation and lipid accumulation (Tsao et al. 2014). For further addressing the roles of IL-4 in lipid metabolism, the present study aimed at characterizing proteins that are regulated by IL-4 in 3T3-L1 mature adipoctyes by proteomic techniques.

For achieving our study goal, the cell model system for 3T3-L1 adipocytes differentiation was firstly established as described (Tsao et al. 2014), and the extent of differentiation was evaluated by Oil-Red O (ORO) staining (Fig. 1). Dose response (10, 25 and $50 \mathrm{ng} / \mathrm{mL}$ ) and time course (30 min to $24 \mathrm{~h}$ ) experiments of IL-4 treatment in mature 3T3-L1 adipocytes were then examined to exclude the potential influences of protein expression patterns by cytotoxic effects induced by IL-4 for establishing optimal experimental condition. No apoptosis or necrosis of 3T3-L1 cells were observed under IL-4 treatment, and no significant difference in total amounts of proteins was observed (data not shown). Then proteomic analysis of putative immediate alterations in protein expression profiles in response to short term IL-4 treatment
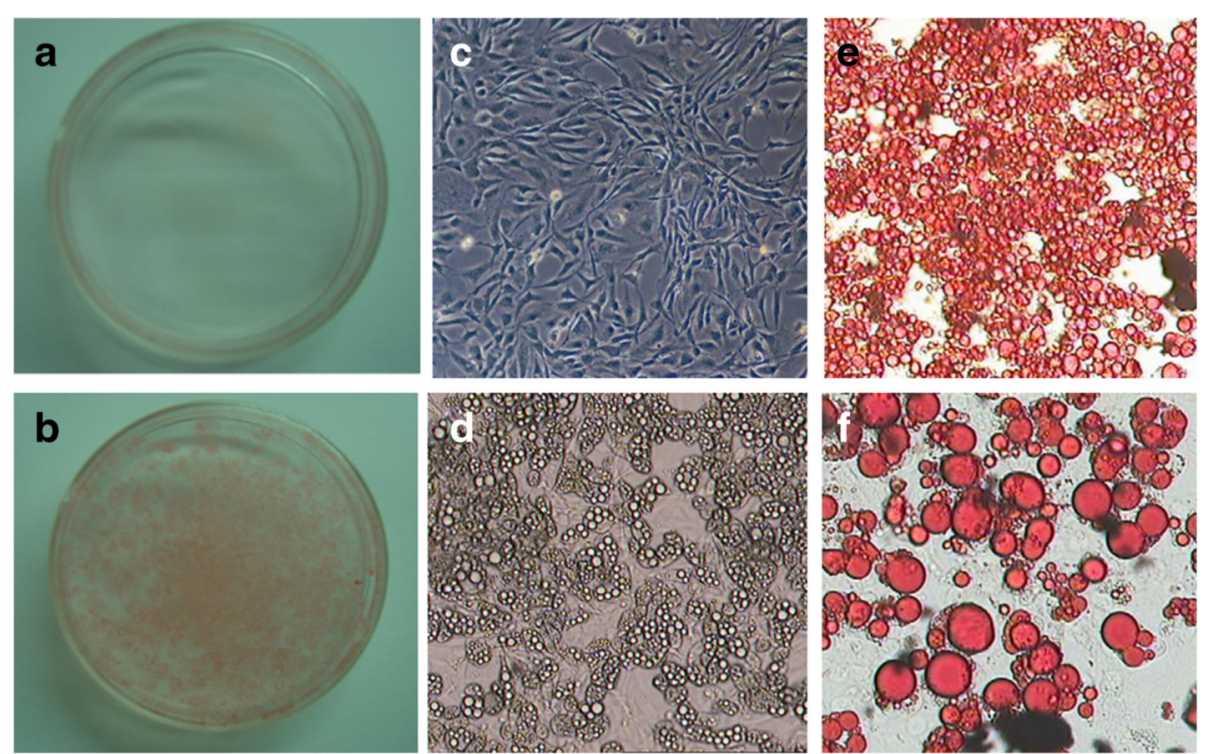

Fig. 1 3T3-L1 pre-adipocytes were cultured for 8 days in the absence (a) or presence (b) of differentiation inducing agents, and subject to Oil-red O staining. The morphological characteristics of cells before and after differentiation were shown as (c) and (d), respectively; (e) and (f) showed the amplified Oil-red $\mathrm{O}$ stating results of $(\mathbf{b})$ 
(30 $\mathrm{min}$ of $50 \mathrm{ng} / \mathrm{mL}$ IL-4) was analyzed. Figure 2 shows the representative 2-dimensional electrophoretic results of mature adipocytes protein expression profile in the absence (A) or presence (B) of IL-4 treatment. Four proteins that were reproducibly up-regulated by IL-4 treatment in three separate experiments were characterized, including Cytochrome $c$ reductase, Pyrophosphatase, ATP synthase $\delta$ chain and Vimentin (Table 1). On the contrary, Valosin, Gelsolin, Alpha enolase ( $\alpha$-enolase) and Vinculin were down-regulated by IL-4 (Table 1 ).

Among the IL-4 up-regulated proteins, genotypes of mitochondrial ATP synthase subunit are reported to be associated with T2DM pathogenesis (Guo et al. 2005). DeLany et al. reveals that induction of ATP synthase $\delta$ chain is accompanied by adipogenesis of adipose-derived adult stem cells for promoting glycolysis and fatty acid metabolism (DeLany et al. 2005). Accordingly, the upregulation of ATP synthase $\delta$ chain by IL- 4 might result in increased ATP synthesis which promotes adipocyte metabolism. Activity of Pyrophosphatase is to hydrolyze pyrophosphate and produce phosphates which in turn participate in cellular activities such as DNA synthesis, ATP production and signal transduction (Ishibashi et al. 2005). The increased levels of Pyrophospatase under IL4 treatment also support the above suggestion that IL-4 might facilitate lipid metabolism by promoting ATP production. Cytochrome $c$ reductase, a component of complex I in mitochondrial electron transport chain, mediates ATP production and proton release for energy supply (Esteitie et al. 2005). The increased levels of Cytochrome $c$ reductase further implicate that efficiency of ATP production may be increased in adipocytes in response to IL-4. Vimentin is one of the important components of cytoskeleton involved in steroid synthesis (Azumi and Battifora 1987). Phosphorylation of Vimentin induces alterations of cytoskeleton which promotes the interaction between lipid droplets and mitochondria, and subsequently steroid synthesis. Moreover, Vimentin is identified in intracellular GLUT4-enriched membranes, suggesting its involvement in glucose transport (Guilherme et al. 2000). Thus, the IL-4-induced Vimentin might contribute to glucose transporter trafficking and glucose uptake (Bluher et al. 2002). Combining the above effects, IL- 4 treatment seems to promote adipocyte metabolism by increasing cellular ATP levels.

On the contrary, levels of several proteins are decreased by IL-4 treatment. Valosin is a member of ATPase protein family (Yamamoto et al. 2004). Therefore, IL-4 might elevate intracellular ATP levels by down-regulating Valosin expression. Gelsolin is a $\mathrm{Ca}^{2+}$ - and polyphosphoinositidemodulated actin-binding protein which serves complicated physiological functions, including regulation of lipid metabolism (Yin et al. 1988). Interestingly, the functions of Gelsolin are in turn regulated by various signaling molecules, including a variety of lipids (Isenberg and Goldmann 1995). Vinculin is another cytoskeleton-associated protein that functions in regulating cell adhesion and motility by transducing force across cell membranes (DeMali et al. 2002; Mere et al. 2005). The IL-4downregulated Gelsolin and Vinculin might be involved in the regulation of cytoskeleton and secretory proteins. The ubiquitous glycolytic enzyme $\alpha$-enolase catalyzes the formation of phosphoenolpyruvate from 2-phosphoglycerate, one of the high-energy intermediates that generate ATP in glycolysis (Pancholi 2001). Thus, $\alpha$-enolase is an enzyme with the functions of regulating glycolysis and cell growth (Saulot et al. 2002). The expression of $\alpha$-enolase is decreased by IL-4, which may result in decreased glycolysis and pyruvate synthesis, and thus mediate glucose metabolism in adipocytes.

Taking the above observations together, most of the IL-4 regulated proteins are related to or involved in
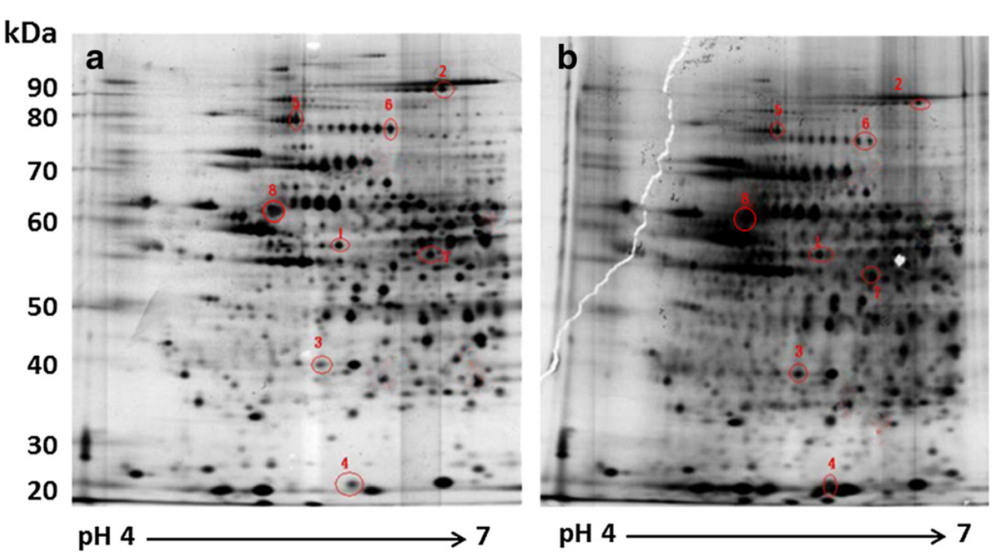

Fig. 2 Representative 2-dimensional protein profiles of mature 3T3-L1 adipocytes. Proteins (120 $\mu \mathrm{g})$ from fully differentiated 3T3-L1 adipocytes in the absence (a) or presence of IL-4 treatment (b; $50 \mathrm{ng} / \mathrm{mL}$ for $30 \mathrm{~min}$ ) were separated by 2-dimensional electrophoresis ( $\mathrm{pH}$ 4-7, 9-15\% SDS-PAGE) and visualized with silver stain 
Table 1 Differentially expressed proteins of mature 3T3-L1 adipocytes by IL-4 treatment

\begin{tabular}{lccl}
\hline Protein identified $^{\text {a }}$ & M.W. (kD) & $\begin{array}{l}\text { Spot no. } \\
\text { in Fig. 2 }\end{array}$ & $\begin{array}{l}\text { Database } \\
\text { accession no. }\end{array}$ \\
\hline $\begin{array}{l}\text { Up-regulated } \\
\text { Cytochrome C reductase }\end{array}$ & 53.4 & 1 & BAB28666 \\
$\begin{array}{l}\text { Pyrophosphatase } \\
\text { ATP synthase D chain }\end{array}$ & 33.1 & 3 & Q9D819 \\
$\quad 18.6$ & 4 & ATPD MOUSE \\
Vimentin & 53.7 & 8 & CAA39807 \\
Down-regulated & & & \\
$\quad$ Vinculin & 117 & 2 & AAH08520 \\
Valosin & 80.6 & 5 & Q8BNF8 \\
Gelsolin & 80 & 6 & Q6PAC1 \\
Alpha enolase & 47.3 & 7 & ENOA MOUSE \\
\hline
\end{tabular}

${ }^{a}$ Each score of above proteins is $>62$, and protein scores greater than 61 are significant $(p<0.05)$

energy metabolism and cytoskeleton dynamics. It suggests that the net effect of $\mathrm{IL}-4$ treatment is to potentiate the increase of ATP levels in adipocytes. The results support our previous observation that adipocytes metabolism might be deviated to catabolism by IL-4 with a favorable condition for lipolysis and inhibiting adipogenesis (Tsao et al. 2014). The catabolized lipids in adipocytes triggered by IL-4 might either be released into periphery or metabolized intracellularlly, and subsequently modulate systemic energy metabolism. However, the underlying mechanism of IL- 4 regulating lipid metabolism awaits further investigation. Despite the needs of further study, the protein alterations in adipocytes under IL-4 treatment revealed in the present study provide novel clues into the nature of the interactions between immunological mediators and adipocyte metabolism.

\section{Conclusion}

We previously reported significant associations between interleukin-4 (IL-4)/IL-4 receptor genotypes and T2DM, as well as $I L-4$ genotypes and HDL-C, which suggest the involvement of IL-4 in lipid metabolism. For further elucidating the role of IL-4 in regulating metabolism, the present study aimed at characterizing the proteins regulated by IL-4 in 3T3-L1 adipocytes. Our results revealed that ATP synthase $\delta$ chain, Cytochrome $c$ reductase, Pyrophsphatase and Vimentin were up-regulated, whereas $\alpha$-enolase, Gelsolin, Vinculin and Valosin were downregulated by IL-4 treatment. IL-4 tends to increase intracellular ATP levels and facilitate energy catabolism in adipocytes by enhancing protein machinery which accelerates ATP synthesis. The results support our previous inference which suggests the metabolism of adipocytes is deviated to catabolism by IL- 4 with a favorable condition for lipolysis.

\section{Materials and methods}

Cell culture and interleukin-4 treatment of 3T3-L1 adipocytes

3T3-L1 pre-adipocytes were maintained in DMEM containing $10 \%$ calf serum in an atmosphere of $5 \% \mathrm{CO}_{2}$ at $37{ }^{\circ} \mathrm{C}$. Differentiation of post-confluent cells was initiated by incubation with $0.25 \mathrm{mM}$ dexamethasone, $0.5 \mathrm{mM} \mathrm{3-}$ isobutyl-1-methylxanthine and $10 \mathrm{ug} / \mathrm{mL}$ insulin for $48 \mathrm{~h}$ (Tsao et al. 2014; Hua et al. 2004). Then cells were cultured in DMEM supplemented with $10 \%$ fetal bovine serum and insulin for the next 4-10 days to fully differentiate. Mature 3T3-L1 adipocytes were treated with $50 \mathrm{ng} / \mathrm{mL}$ recombinant IL-4 (Millipore) for $30 \mathrm{~min}$ after $2 \mathrm{~h}$ of serum starvation, then cell lysates were harvested and the protein expression profiles were examined as described below.

\section{Oil Red $O$ staining}

Lipid accumulation during 3T3-L1 differentiation was confirmed by Oil Red O staining. Cells were washed twice with phosphate buffered saline, fixed in $10 \%$ formalin neutral buffered solution for $10 \mathrm{~min}$ at room temperature, rinsed with distilled water and dried after they were induced. Then cells were stained with Oil Red $\mathrm{O}$ (composed of $0.6 \%$ Oil Red O dye dissolved in isopropanol and water, 6:4) for $30 \mathrm{~min}$ and washed with distilled water (Tsao et al. 2014; Madsen et al. 2003). The results showed that over $90 \%$ of cells exhibited typical mature adipocytes morphology after 8 days of induction.

\section{Proteomic techniques}

After cells were treated with IL-4, cell lysates were obtained with lysis buffer containing protease inhibitors (8 M urea, 4 \% 3-[(3-cholamidopropyl)dimethylammonio]-1-propanesulfonate [CHAPS], $1 \mathrm{mM}$ phenylmethylsulfonyl fluoride [PMSF] and $100 u \mathrm{~g} / u \mathrm{~L}$ leupeptin) for $30 \mathrm{~min}$ on ice, then sonicated by $10 \mathrm{~s}$ interval for 3 times. The sonicated cell lysates were frozen at $-20{ }^{\circ} \mathrm{C}$ for $30 \mathrm{~min}$, and dried out using speed vacuum. The dried cell lysates were re-solubilized in lysis buffer, centrifuged with $11,000 \mathrm{rpm}$ for $30 \mathrm{~min}$ at $18{ }^{\circ} \mathrm{C}$. Then supernatant were collected and the proteins in cell lysates were separated by isoelectric focusing (with $\mathrm{pH}$ range 4-7) and $9 \sim 15 \%$ gradient SDS-PAGE electrophoresis sequentially. The 2-dimensional electrophoresis gel containing separated proteins was visualized by sliver staining, then the protein spots that showed great alterations before and after IL-4 treatment were cut and washed by sterile distilled water, followed by $50 \mathrm{mM} \mathrm{NH} 4 \mathrm{HCO} / 100 \%$ acetone nitrite (v/v: 3:2), and de-stained with $0.1 \mathrm{~g} \mathrm{~K} 3 \mathrm{Fe}(\mathrm{CN}) 6$ plus sodium thiosulfate solubilized in $50 \mathrm{ml}$ distilled water. The cut gel particles were washed by $25 \mathrm{mM} \mathrm{NH} 4 \mathrm{HCO} 3$ and $100 \%$ acetonitrite for dehydration, and soaked in trypsin overnight for in gel digestion, then each sample was applied on the anchor chip for MALDI-TOF analysis. 


\section{MALDI-TOF analysis}

MALDI-TOF analysis was conducted as previously described (Wang et al. 2002). Briefly, tryptic peptide solutions were mixed with an equal amount of CHCA matrix $(10 \mathrm{mg} / \mathrm{mL}$ in $60 \%$ cetonitrite $/ 0.3 \%$ trifluoroacetic acid), spotted onto the sample plates and air-dried. Reflectron mass spectrometric analyses were performed in the Proteomics Core Laboratory in Chang Gung University. Acquired spectra were searched against MASCOT databases. A positive score was defined to be greater than 62 for each peptide ion. Proteins were identified based on multiple matches to peptides from the same protein by MASCOT score.

\section{Abbreviations \\ a-enolase: Alpha enolase; CHAPS: 3-[(3-cholamidopropyl)dimethylammonio]- 1-propanesulfonate; HDL-C: High density lipoprotein-cholesterol; HSL: Hormone sensitive lipase; IL-4: Interleukin-4; MS: Metabolic syndrome; PMSF: Phenylmethylsulfonyl fluoride; T2DM: Type 2 diabetes mellitus; Th2: Type $2 \mathrm{~T}$ helper cell.}

\section{Competing interests}

The authors declare that they have no competing interests.

\section{Authors' contributions}

CYC carried out the experiments, proteomic studies, sequence alignment and analysis. SMY participated in the manuscript drafting, design of the study and data interpretation. CYH participated in design of the study, data interpretation, and revising the manuscript draft critically for important intellectual content. LHF participated in the manuscript drafting, design of the study and statistical analysis. SYL conceived of the study, participated in its design and coordination, drafting the manuscript, and giving final approval of the manuscript. All authors read and approved the final manuscript.

\section{Acknowledgements}

We thank Prof. Jau-Song Yu from Proteomics Core Laboratory at Chang Gung University for the technical assistance of the proteomic experiments and data analysis. This work was supported by grants $\mathrm{CHRH}-102-25$ from Cheng Hsin General Hospital, and SKH-8302-103-NDR-10 from Shin Kong Wu Ho-Su Memorial Hospital, Taipei, and in part by grants MOST101-2911-I-010008, MOST101-2320-B-010-052-MY3 and MOST102-2320-B-241-004-MY3 from the Ministry of Science and Technology, Taiwan, Republic of China.

\section{Author details}

${ }^{1}$ Department of Nursing, College of Medicine \& Nursing, Hungkuang University, Taichung, Taiwan. ${ }^{2}$ Department of Clinical Pathology, Cheng Hsin General Hospital, Taipei, Taiwan. ${ }^{3}$ Department of Biotechnology and Laboratory Science in Medicine, National Yang-Ming University, Taipei, Taiwan. ${ }^{4}$ Department of Pathology and Laboratory Medicine, Shin Kong Wu Ho-Su Memorial Hospital, Taipei, Taiwan. ${ }^{5}$ School of Medical Laboratory Science and Biotechnology, Taipei Medical University, Taipei, Taiwan. ${ }^{6}$ School of Medicine, Fu-Jen Catholic University, New Taipei City, Taiwan.

\section{Received: 18 September 2014 Accepted: 15 April 2015}

\section{Published online: 04 June 2015}

\section{References}

Azumi N, Battifora H (1987) The distribution of vimentin and keratin in epithelial and nonepithelial neoplasms. A comprehensive immunohistochemical study on formalin- and alcohol-fixed tumors. Am J Clin Pathol 88:286-296

Bluher M, Michael MD, Peroni OD, Ueki K, Carter N, Kahn BB et al (2002) Adipose tissue selective insulin receptor knockout protects against obesity and obesity-related glucose intolerance. Dev Cell 3:25-38

Bradley RL, Cleveland KA, Cheatham B (2005) The adipocyte as a secretory organ: mechanisms of vesicle transport and secretory pathways. Recent Prog Horm Res 56:329-358
Chaldakov GN, Stankulov IS, Hristova M, Ghenev PI (2003) Adipobiology of disease: adipokines and adipokine-targeted pharmacology. Curr Pharm Des 9:1023-1031

Chang YH, Ho KT, Lu SH, Huang CN, Shiau MY (2012a) Regulation of glucose/lipid metabolism and insulin sensitivity by interleukin-4. Int J Obes (Lond) 36:993-998

Chang YH, Huang CN, Shiau MY (2012b) Association of IL-4 receptor gene polymorphisms with high density lipoprotein cholesterol. Cytokine 59:309-312

Cornelius P, MacDougald OA, Lane MD (1994) Regulation of adipocyte development. Annu Rev Nutr 14:99-129

DeLany JP, Floyd ZE, Zvonic S, Smith A, Gravois A, Reiners E et al (2005) Proteomic analysis of primary cultures of human adipose-derived stem cells: Modulation by adipogenesis. Mol Cell Proteomics 4:731-740

DeMali KA, Barlow CA, Burridge K (2002) Recruitment of the Arp2/3 complex to vinculin: coupling membrane protrusion to matrix adhesion. J Cell Biol 159:881-891

Elbe-Burger A, Egyed A, Stingl G, Klubal R, Mann U, Rappersberger K et al (2002) Overexpression of IL-4 alters the homeostasis in the skin. J Invest Dermatol 118:767-778

Esteitie N, Hinttala R, Wibom R, Nilsson H, Hance N, Naess K et al (2005) Secondary metabolic effects in complex I deficiency. Ann Neurol 58:544-552

Garcia-Zepeda EA, Combadiere C, Rothenberg ME, Sarafi MN, Lavigne F, Hamid Q et al (1996) Human monocyte chemoattractant protein-4 is a novel CC chemokine with activates on macrophage, eosinophils, and basophils induced in allergic and non-allergic inflammation that signals through the CC chemokine receptors (CCR)-2 and-3. J Immunol 157:5613-5626

Guilherme A, Emoto M, Buxton JM, Bose S, Sabini R, Theurkauf WE et al (2000) Perinuclear localization and insulin responsiveness of GLUT4 requires cytoskeletal integrity in 3T3-L1 adipocytes. J Biol Chem 275:38151-38159

Guo LJ, Oshida Y, Fuku TNT, Fujita Y, Kurata M, Sato Y et al (2005) Mitochondrial genome polymorphisms associated with type-2 diabetes or obesity. Mitochondrion 5:15-33

Ho KT, Shiau MY, Chang YH, Chen CM, Yang SC, Huang CN (2010) Association of IL-4 promoter polymorphisms in Taiwanese patients with type 2 diabetes mellitus. Metabolism 59:1717-1722

Hua K, Deng J, Harp JB (2004) IL-4 inhibits platelet-derived growth factor-induced preadipocyte proliferation. Cytokine+ 25:61-67

Isenberg G, Goldmann WH (1995) Actin-binding protein-lipid interaction. In: The Cytoskeleton. Greenwich, CT/London, pp 169-204

Ishibashi T, Yamagata Y, Hayakawa H, Ito R, Miyazawa M, Yamagata Y et al (2005) Mammalian enzymes for preventing transcriptional errors caused by oxidative damage. Nucl Acids Res 33:3779-3784

Kang K, Reilly SM, Karabacak V, Gangl MR, Fitzgerald K, Hatano B et al (2008) Adipocyte-derived Th2 cytokines and myeloid PPARdelta regulate macrophage polarization and insulin sensitivity. Cell Metab 7:485-495

Lyon CJ, Law RE, Hsueh WA (2003) Minireview: adiposity, inflammation, and atherogenesis. Endocrinology 144:2195-2200

Madsen L, Petersen RK, Sørensen MB, Jørgensen C, Hallenborg P, Pridal L et al (2003) Adipocyte differentiation of 3T3-L1 preadipocytes is dependent on lipoxygenase activity during the initial stages of the differentiation process. Biochem J 375:539-549

Mere J, Chahinian A, Maciver SK, Fattoum A, Bettache N, Benyamin Y et al (2005) Gelsolin binds to polyphosphoinositide-free lipid vesicles and simultaneously to actin microfilaments. Biochem J 386:47-56

Pancholi V (2001) Multifunctional a-enolase: its role in diseases. Cell Mol Life Sci 58:902-920

Paul WE (1997) Interleukin 4: signaling mechanisms and control of T cell differentiation. Ciba Found Symp 204:208-216

Paul WE, Seder RA (1994) Lymphocyte responses and cytokines. Cell 76:241-251

Ricote M, Welch JS, Glass CK (2000) Regulation of macrophage gene expression by the peroxisome proliferator-activated receptor-gamma. Horm Res 54:275-280

Saulot V, Vittecoq O, Charlionet R, Fardellone P, Lange C, Marvin L et al (2002) Presence of autoantibodies to the glycolytic enzyme alpha-enolase in sera from patients with early rheumatoid arthritis. Arthritis Rheum 46:1196-1201

Sorisky A (1999) From preadipocyte to adipocyte: differentiation-directed signals of insulin from the cell surface to the nucleus. Crit Rev Clin Lab Sci 36:1-34

Trayhurn P, Beattie JH (2001) Physiological role of adipose tissue: white adipose tissue as an endocrine and secretory organ. Proc Nutr Soc 60:329-339

Tsao CH, Shiau MY, Chuang PH, Chang YH, Hwang J (2014) Interleukin-4 regulates lipid metabolism by inhibiting adipogenesis and promoting lipolysis. J Lipid Res 55:385-397 
Wang Y, Xu A, Knight C, Xu LY, Cooper GJ (2002) Hydroxylation and glycosylation of the four conserved lysine residues in the collagenous domain of adiponectin: Potential role in the modulation of its insulin-sensitizing activity. J Biol Chem 277:19521-19529

World Health Organization (2014) Obesity and Overweight. http://www.who.int/ mediacentre/factsheets/fs311/en/, updated August 2014

Yamamoto S, Tomita Y, Hoshida Y, Nagano H, Dono K, Umeshita K et al (2004) Increased expression of valosin-containing protein (p97) is associated with lymph node metastasis and prognosis of pancreatic ductal adenocarcinoma. Ann Surg Oncol 11:165-172

Yin HL, lida K, Janmey PA (1988) Identification of a polyphosphoinositidemodulated domain in gelsolin which binds to the sides of actin filaments. J Cell Biol 106:805-812

Submit your manuscript to a SpringerOpen ${ }^{\odot}$ journal and benefit from:

- Convenient online submission

Rigorous peer review

- Immediate publication on acceptance

- Open access: articles freely available online

- High visibility within the field

- Retaining the copyright to your article

Submit your next manuscript at $\downarrow$ springeropen.com 